\title{
Modeling the Optimal Path of Industrial Pollution Abatement under Tradable Permit and Seawater Cleaning Project in the Bohai Sea
}

\author{
Xiaojie Nie ${ }^{1}$ \\ ${ }^{1}$ Department of Economics, College of Economics and Management, Dalian Ocean University, China \\ Correspondence: Xiaojie Nie, Department of Economics, College of Economics and Management, Dalian Ocean \\ University, China. E-mail:nxj@dlou.edu.cn
}

Received: November 21, 2017

Accepted: December 18, 2017

Online Published: January 8, 2018

doi:10.5539/enrr.v8n1p39

URL: https://doi.org/10.5539/enrr.v8n1p39

\begin{abstract}
For a long term the accumulation of pollutants in the Bohai Sea brings great damage to marine ecosystem, huge economic and social losses. This paper sets up a frame work modeling the optimal path of industrial pollution abatement under tradable permit and seawater cleaning project. Three sub-models are set up which reveal pollution-fish stock interaction, industrial pollution abatement under tradable permit, seawater cleaning project, respectively. Then in next session we introduce dynamic optimization problem which combines contains two state equations, which correspond to two state variables fish stock $x$ and pollution stock $m$, respectively; four control variables industrial production $y$, volume of pollution abatement $z$, volume of sea water cleaning $S$ and catch of fish $h$, respectively. To maximum benefit of fishery, we follow and introduce the optimal solution of four control variables obtained from dynamic optimization.
\end{abstract}

Keywords: industrial production, pollution abatement, sea water cleaning, fish stock, optimal path

\section{Background}

\subsection{Pollution Impacts}

The Bohai Sea has been famous for its abundance natural resources and used to be the economic lifeline for tens of thousands of fishermen in surrounding regions, but nowadays it becomes the heaviest polluted area in China. The most direct results of industry-leading economy are high energy consumption and environmental damage. Pollution increases sharply accompanied with rapid economy growth. Land-based discharge from industries and human habitation is the main source of pollution. Industrial emissions account for around $80 \%$ of total pollutants into the Bohai Sea (Marine Environment Quality of the Bohai Sea, 2009). There are 105 pollution discharge outlets to the Bohai Sea, which discharge 2.8 billion tons of polluted water per year (accounted for $32 \%$ of total polluted water discharged in China), total pollutants 700,000 tons (accounted for $47.7 \%$ of total pollutants discharged in China) (National Marine Environment Quality Bulletins, 2004-2009). Another important channel of land-based pollutants into the Bohai Sea is flows' carrying. There are 45 major rivers in the Bohai Sea basin, mostly surrounded by distribution-intensive industrial zone which discharge large amounts of sewage into the river each year, causing serious pollution to the rivers. The monitoring results from National Marine Monitoring Centre indicate that in recent years (2003-2008), the major rivers annually carry average 846,719 tons pollutants into the sea (National Marine Environment Quality Bulletins, 2004-2009). The special geographical condition of the Bohai Sea decreases its self-circulated ability which needs around 40 years for whole sized water cycle, leading to a lack of self-cleaning ability. The accumulation of pollutants in sea water and seabed brings great damage to marine ecosystem, huge economic and social losses.

This pollution has substantial detrimental effects on the Bohai Sea fish stocks and the quality of the landings. Seawater pollution in the Bohai Sea has caused enormous economic losses and damage of ecosystem. In recent years, fishery biodiversity in the Bohai Sea decreased obviously. The stock of traditional commercial species appeared a drastic drop, and a younger -aged, miniaturization trend, juveniles accounted for more than $60 \%$ of the total catch. Over the years, small yellow fish and hairtail do not form a fishing season, pomfret and mackerel are also in risk. As one of the major specialty in the Bohai Sea, in 70's of last century, annual production of shrimp was about 2 million tons; the highest year was around 34,000 ton; in recent years, production fell down to a thousand tons. "It brings biological extinction because of $100 \%$ spawning ground polluted. Fish hermaphrodite rate has been up to $32 \%$, more and more fish is losing reproductive capacity." 


\subsection{Water Cleaning Path of the Bohai Sea}

In 1972 toxicants were found in seafood from the Bohai Sea by export commodities inspection departments, thus the government put forward marine environment protection problem. In 1978 a key scientific research - "Study on Prevention of pollution in the Bohai Sea \& the Yellow Sea" was released by National Science Committee. In 1990 the final report with 300,000 characters and 98 atlases was published by China Science Press. Experts gained 1400,000 data through a decade survey, investigation and assessment of environment. The report analyzed pollutant sources, environmental chemistry, environmental physics, environment capacity, and pushed forward the monographic studies on emphasis areas. It provides the scientific and projective database for later research and projects. North America "World Daily" (June 9 ${ }^{\text {th }}$, 1998) reported the Bohai Sea pollution with the title of "The Deterioration of Ecological Equilibrium Will Lead the Bohai Sea Dead". The Bohai Sea was compared to the Black Sea in the article because these two seas have similar geological structure and faced the same problem. But per $\mathrm{km}^{3}$ sea water in the Bohai Sea accepts 7,100 tons net pollutants (without water) per year, 350 times as in the Black Sea. In 1998 National Ocean Bureau declared to the public after 22 days liaison law enforcement in the Bohai Sea: "Ad libitum pollutants discharge and blind construction is pushing progressive deterioration of the ecosystem in the Bohai Sea. It's the time to take effective actions on prevention from the evil consequence of biological extinction."

In 2001 National Environmental Protection Agency started to discuss the implementation details of "the Blue Sea Project" concerning pollution treatment system of the Bohai Sea which was based on "The Study on Prevention of pollution in the Bohai Sea \& the Yellow Sea" (National Science Committee, 1990). "The Blue Sea Project" was implemented formally in Sep. 2001. Total cost budget was 6.7 hundred million USD for three stages treatment of the sea water environment before 2015, aiming to a preliminary improvement of the Bohai Sea ecosystem (Focus on the Bohai Sea: series report, 2001). There was detailed analysis of social economics, total quantity of pollutants, sources and entering modes of pollutants; at the same time made "Hierarchical Structure of Pollution Controlling System" as the implementation plan. Simply from technical angle it was a comprehensive and detailed, looked like a perfect study. But it failed in later practices. By the end of 2003, 1.74 hundred million USD were invested into part of items establishment of the project to achieve the goals in the first stage. In 2004 the first stage implementation result was submitted to the government and published by National Environmental Protection Agency. The report adopted a large quantity of data as evidences to illustrate that the administration sectors had perfectly achieved the goals of the first stage.

In August 2006, on State Council conference - "the Bohai Sea Environment Protection Operations" National Vice-Premier Wu Peiyan sharply pointed out the problems of increasing pollutants, polluted area, red tides and serious pollution accidents in the Bohai Sea. Thus the "Blue Sea Project" was suspended indefinitely as its performance and efficiency were inquired by government and society. As a implementation plan does not force the other side of the analysis, there is no power on its own terms, it only sets out to achieve the goals and timetable. The inefficiency of implementation of the "Blue Sea Project" is due to three reasons: the plan is only a schedule of technical objectives, lack of feasibility analysis; imperfect outfit laws and regulations of "Marine Environment Protection Law"; many-sided law enforcement and responsibility crossover which greatly decreased the efficiency of implementation; pollution tax existence in name only for enterprises because of local Protectionism. National Environmental Protection Agency failed to play leading and coordinated role among concerning administrations and complex management regime.

At the beginning of 2001 before "Blue Sea Project", Professor Dai Zhongdao put forward the application of "Colloid Cradle Theory" to reduce sea water pollution in Qingdao Marine Open Forum Proceeding "Disasters in Marine Industrial and Countermeasures". Professor Dai illustrated the principle and technology of sea water self-purification progress in the proceeding: "by spraying a certain proportion of limewater, high efficiency and low toxicity drugs to mud extracted from the Yellow River in red tide area, made the mud hydrolyzed to be hydroxide with charge which could absorb eutrophic elements, heavy metal ions, germ and algae, as to clean the sea water and effectively control red tides." Advantages of the project are lower cost (around 80\% of the "Blue Sea Project"), scientific and effective (these had been proved in other practices in last 40 years). But it's lack of comprehensive cleaning function, as well as the germ mud would fall down and cover the seabed forever. The better way is to apply "Colloid Cradle Theory" as an assistant method to accelerate sea water cleaning progress in the Bohai Sea pollution treatment project.

Development and Reform Commission in July 2006 launched "the Bohai Sea Environmental Protection Master Plan" preparation. August 10, the leading group of the "planning" preparation was set up by the Ministry of Science, Technology Development and Reform Commission, Ministry of Finance, the Ministry of Construction, Ministry of Communications, Ministry of Water Resources, Ministry of Agriculture, Environmental Protection 
Administration, National Forestry Administration, National Oceanic Bureau and 5 enterprise groups. It concerned much interests and complex relationship. The new "the Bohai Sea Environmental Protection Master Plan" announced by August, 2008 revealed that the National Oceanic Bureau will play a lead role instead of Environmental Protection Agency. However, if the Environmental Protection Agency can't coordinate all aspects of the relationship in the administrative system, the National Oceanic Bureau who has the same hierarchy with the former has the ability to solve the problem? What's the fate of "Bohai Sea Environmental Protection Master Plan" with an additional 5.8 hundred million USD cost (Liu \& Lu, 2006)? We have to consider the root causes of socio-economic issues. The Bohai Sea region is an important industrial base in China, which contributes $16 \%$ of total GDP (China Statistic Yearbook, 2008). Any policy maker has to face to the alternatives in the Bohai Sea region, on the one hand is a fragile ecological environment; the other hand is enormous pressure on the industrialization, social public policy options are extremely limited (Zheng, 2007).

\subsection{Development of the Pollution Levy System in China}

Discussion of a possible pollution charge system began in China after the Stockholm Conference of 1972. The idea was formally adopted by the central government in 1978, when the Leaders Group for Environmental Protection in the State Council provided a work report to the Central Committee of the Chinese Communist Party. The report stated that "Pollution source control should be an important component of environmental management; fees should be charged against pollution discharge; and environmental protection authorities, in cooperation with other departments, should set up a detailed levy schedule." Article 18 of the "Trial Environmental Protection Law," which was enacted in 1979, stated that "the levy should be imposed on pollution discharges which exceed national pollution discharge standards, based on quantity and concentration of discharges and levy fee schedules established by the State Council." Several local governments immediately began experimenting with charges, and by the end of 1981, 27 of China's 29 provinces, autonomous regions and municipalities had established programs of some type.

Chinese government issued an "Interim Procedure on Pollution Charges" in February, 1982. The procedure defined the system's objectives, principles, levy standards, levy collection methods, and principles for fund use. Nationwide implementation rapidly followed. The levy system is based on a discharge standard system, and only discharges exceeding the standards are subject to a fee. However, the regulations also specify that payment of the levy does not exempt polluters from legal liability for above-standard discharges. Thus, the levy system incorporates elements of both market-based and command-and-control regulation.

In the water pollution levy system, polluters report their emissions, and the local environmental authorities are responsible for verification. Self-reporting is quite extensive in the Chinese system. All polluters are required to register with local environmental authorities, and to provide information in the following categories:

- basic economic information (sector, major products and raw materials);

- $\quad$ production process diagrams;

- volume of water use and waste water discharge; pollutant concentrations in waste water;

- mandated ambient quality level for receiving water; and

- discharge timing.

The local environmental authorities check polluter reports in several ways, including: internal consistency of reported data; consistency with material balance models; historical data from the facility; direct monitoring; and surprise inspections. When the data are cleared by the environmental authorities, they are used for assessments computed from the levy calculation manual. Penalties are imposed for false reporting and/or non-cooperation with government inspections. Polluters have a 20-day grace period to pay the monthly/quarterly levy, after which the required payment increases by $0.1 \%$ per day. Intractable disputes are resolved by the local courts or higher-level environmental authorities. Polluters are required to report increased discharges, and rebates are possible when pollution reductions are verified. The levy can be reduced or even eliminated at the discretion of local regulators after appropriate inspections. The levy may also be postponed if the polluter cannot afford to pay it, although reductions or exemptions are not allowed in such cases. Of course, this degree of latitude introduces considerable variation in regional enforcement practices. These disparities are the object of frequent criticism although, as several recent papers have noted, they seem roughly consistent with the tenets of environmental economics (Dasgupta, NI, \& Wheeler, 1997). 


\section{Model I. A Bio-economic Model of Fishery-pollution Interactions}

\subsection{Loading into the Environment}

Once the contaminants have been discharged into the environment then the effluent is diluted by the receiving water. Models are available to calculate the rate of mixing and molecule speciation, but for simplification it will be assumed that the effluents become fully mixed on entering the system and that the contaminant exists in one form only. Further to the dilution by mixing there are other processes that will modify the final concentration of the contaminant in the water. Given that the environment is of a constant volume, then the concentration of contamination may be approximated by Vollenweider's equation (Richard, Vollenweider, Talling, \& Westlake, 1974):

$$
\frac{d C}{d t}=I-\varepsilon \cdot C
$$

Subject to

$$
I=\frac{m}{v}
$$

Where:

$C$ - concentration of contaminant $\left(\mathrm{g} \mathrm{m}^{-3}\right)$

$\mathcal{E}$-total rate of self-purification, including physical self-purification, chemical self-purification and biological self-purification

$m$-pollution stock

$v$ - total volume of sea water in the Bohai Sea

The hydraulic washout coefficient is a measure of flushing, and refers to the number of times the water is changed per year. The sedimentation rate measures the percentage of contaminant that is lost each year. From this a time-specific form can be derived as follows:

$$
C_{E}(t)=a \cdot e^{-\varepsilon t}+b \cdot\left(1-e^{-\varepsilon t}\right)
$$

Subject to

$$
\begin{gathered}
a=C(0)-b \\
b=\frac{I}{\varepsilon}
\end{gathered}
$$

\section{Wheneollution loading in environment}

The natural level of contamination in the system, termed the background level, could be found by expanding the time-specific form to infinity if all the variables are held constant. The following alternative equation can be used:

$$
\begin{gathered}
t \rightarrow \infty \\
C_{E}=b=I / \varepsilon=\frac{m}{\varepsilon \cdot v}
\end{gathered}
$$

\subsection{Loading in the Stock}

The next step is to find the internal level of contaminants within the fish stock as opposed to the level in the environment. This enables the accumulation of contamination in the stock to be traced in the model. The model advanced simplifies the situation by defining the concentration in the stock as being dependent on two variables and time. If it is accepted that both input and output are determined by a constant ratio of the source, then the concentration in the stock becomes (Collins, Stapleton, \& Whitmarsh, 1998): 


$$
C_{F, t_{0}}=C_{E, t_{0}} Q(1-O)
$$

Where:

$C_{F}$ - pollution loading in fish stock

$Q$ - pollution input coefficient into fish

$O$ - pollution output coefficient from fish

The input coefficient measures the fraction of external concentration that becomes internal (i.e. uptake), while the output coefficient measures the fraction of internal loading that is removed (i.e. elimination). Subsequently the concentration in the next time period becomes:

$$
C_{F_{t+1}}=\left(C_{F_{t}}+C_{E_{t+1}} Q\right)(1-O)
$$

From above two functions, time-specific form of pollution loading in fish stock can be specified as:

$$
C_{F}(t)=C_{F}(0) \cdot(1-O)^{t}+\sum C_{E}(t) \cdot Q \cdot(1-O)
$$

\subsection{Effects in the Stock}

As it is now possible to calculate the concentration of the contaminant in the stock, it is necessary to have a model that transforms this term into changes in mortality and fecundity. A simplified linear relationship can be expressed as:

Where:

$$
Z=\omega C_{I}+\gamma
$$

$Z$ - pollution introduced mortality

$C_{I}$ - concentration of internal level of contaminate in fish stock

$\omega$ - marginal impact of contaminant on mortality

$\gamma-$ constant term related to the threshold level of contamination

By this method concentrations below the threshold level can be ignored as they induce no change in fish mortality at that age and at that time. Threshold levels are determined with respect to different fish age groups. In addition to the direct effects of mortality in the stock the same type of relationship can be given for changes in fecundity (Welch, 1992). This can be expressed as:

$$
K=k C_{I}+\gamma
$$

Where:

$K$ - fish reduction in fecundity

$\kappa$ - marginal impact of contaminant on fecundity

Since we lack statistics on fish age and number in the Bohai Sea, for the threshold level we introduce the average level of fish stock and analyze the pollution impacts on the stock instead of the number change of each age group. Thus pollution-induced mortality $(Z)$, which will cause further changes in the stock, can now be introduced into the fish growth function such that:

$$
\begin{gathered}
x_{t+1}=x_{t} \cdot(1-M) \cdot\left(1-Z_{t}\right)-h_{t} \\
x_{t+1}=x_{t} \cdot\left(1-M-Z_{t}+Z_{M, t}\right)-h_{t}
\end{gathered}
$$

Where:

$x-$ fish biomass

$h$ - catch of fish

$M$ - natural mortality of fish 
The uncontaminated situation of the stock-recruitment relationship can be expressed by Beverton-Holt model (Beverton \& Holt, 1957):

$$
R=A \cdot X /(B+X)
$$

Where:

$R$ - number of recruits

$X$ - spawning stock size

$A$ - maximum number of recruits

$B$ - spawning stock size required for $R=X$

In addition to the action of contamination in increasing total mortality levels the model also enables changes in reproductive fitness to be analyzed, i.e. the fecundity of the age groups will change, dependent on the internal level of contaminant. The expression for the total number of eggs produced may be given by:

$$
E_{g_{t}}=\sum\left(F_{t, a} N_{t, a}\right)
$$

Where:

$E_{g}-$ number of eggs produced

$N_{t, a}$ - fish number at age a in year $t$

$F_{t, a}-$ fish fecundity at age a in year $t$

Introduce the pollution impact parameter of fecundity to the function, it can be transformed as:

$$
E_{g_{t}}=\sum\left(F_{t, a} N_{t, a}(1-K)\right)
$$

The Beverton-Holt model with pollution impacts can be specified as:

$$
R=\frac{A \cdot X}{B+X} \cdot \varphi(K)
$$

Subject to

$$
\varphi(K)=\sum\left(F_{t, a} \cdot N_{t, a} \cdot(1-K)\right)
$$

Where:

$K$ - fish reduction in fecundity

$\varphi(K)$ - function for the total number of eggs produced effected by pollution

\section{Model II. Modeling Industrial Pollution Abatement under Tradable Permit}

In a contaminated area with $\mathrm{n}$ polluting firms, the government sets a limit $\mathrm{M}$ under the environmental capacity of the total amount of pollution. Assume that the government allocates the initial emission permit $r$ to a firm under total control principle and emissions trading in order to perfect competition, and then the $\mathrm{n}$ firms owning discharge rights constitute suppliers and demanders in the market. For any firm, the initial emission permit $r_{0}$ and price $\mathrm{p}_{0}$ are the exogenous variables. Generally, for each firm to develop its own sewage strategy under fix $r_{0}$ and $p_{0}$, there are three sewage strategic alternatives according to their own different resources and capabilities:

I. Introduce advanced pollution control equipment to form the scale effect, lower the marginal cost of pollution

II. without carrying out technical innovation under a rigid production planning, enterprises select the optimal discharge strategy under the current product capacity and pollution control cost

III. with completely independent producers' power, enterprises adjust the production scale to control the emissions

The basic assumptions of the model are as flowing: 


\section{- Assumption I}

The objective is to maximize profit of enterprise. Demand of emission $r$ is the monotone increasing function of production $\mathrm{y}$.

\section{- Assumption II}

All pollutants are uniformly mixed pollutants, then the cost of pollution abatement is the function of emission reduction, that $C(z)$. In general, under the premise of constant technological level, with the increase of emission reduction, marginal abatement cost increases, ie $C^{\prime}(z)>0, C^{\prime \prime}(z) \geq 0$. With technological innovation under present scale, the marginal abatement cost decreases along with emission reduction, ie $C^{\prime}(z)>0, C^{\prime \prime}(z) \leq 0$. Here we assume all the firms will adopt technological innovation under present scale to ensure that is $C(z)$ concave, which would be available to provide a solution of dynamic optimization model later on.

\section{- Assumption III}

The model assumes that the government practices strict control and penalty system, that firms do not exist over effluent out of standard. The available transaction volume of tradable permit of the firm can be expressed as:

$$
r-r_{0}-z
$$

$r-$ industrial emission

$r_{0}-$ initial emission permit

$z$ - volume of pollution abatement

The production profit function of the firm is

$$
V(y)=p \cdot y-c(y)
$$

Where

$p$ - price of industrial production

$y$ - production volume of industry

$c(y)-$ cost function of the firm

With previous assumptions, the industry optimization problem under tradable permit can be described as a non-linear function (Li, 2008):

$$
\max V(y)-C(z)-p_{0}\left(r-r_{0}-z\right)^{2}
$$

Subject to

$$
\begin{gathered}
r=F(y)=\Sigma \rho_{i j} \cdot y \\
y=F^{-1}(r)=\frac{r}{\rho_{i j}}
\end{gathered}
$$

Qiheremission coefficient of pollutant $i$ under technology $j$

$F(y)$ - function of industrial emission

The emission coefficient $\rho_{i j}$ for different production and technology is available to be access to in Industrial Pollution Emission Coefficient Manual from The First National Census on Pollution Sources (State Council, 2008). At this point, the firm's optimization problem can be described as:

$$
\max V(r)-C(z)-p_{0}\left(r-r_{0}-z\right)^{2}
$$

Since $r$ has positive correlation with $y$, it can be assumed that $r$ is the strict concave function of $V$, that is, $V^{\prime}(r)>0$ and $V^{\prime \prime}(r)<0$.

1) Under the rigid production plan

Where $r$ is immutable, the model is equivalent to minimize the total cost of pollution control model: 


$$
\min C(z)+p_{0}\left(r-r_{0}-z\right)^{2}
$$

According to the necessary condition, the solution should be:

$$
C_{z}=2 p_{0}\left(r-r_{0}-z\right)
$$

2) Under completely independent producers' power

When the firm can freely adjust the scale of production, the profit maximization condition is:

$$
\max V(r)-C(z)-p_{0}\left(r-r_{0}-z\right)^{2}
$$

According to the necessary condition, the solution of the problem should be:

$$
V_{r}=2 p_{0}\left(r-r_{0}-z\right)=C_{z}
$$

3) The direct abatement cost function $C(z)$ specified

For k pollutants, the environmental engineering literature suggests that an appropriate joint cost function for plant i should include the following variables (Dasgupta, Huq, Wheeler, \& Zhang, 1996):

$$
C_{i}(z)=f\left(w_{i}, \frac{d_{i}}{g_{i}}, p_{j}, u_{i}\right)
$$

Where

$C_{i}(z)$ - total annual cost of abatement for the plant

$w_{j}$ - total annual wastewater volume

$d_{i}$ - emission after abetment

$g_{i}-$ emission before abatement

$p_{j}$ - vector of input prices at location $\mathrm{j}$

$u_{i}-$ vector of relevant plant characteristics (sector, age, ownership, productive efficiency, etc.)

$f_{i} / g_{i}-$ vector of effluent/influent ratios for $\mathrm{n}$ pollutants, which can be interpreted either as concentration ratios or volume ratios (since waste water volume is constant across influent and effluent for each plant, it cancels out of the concentration ratio).

For the kth pollutant, the marginal abatement cost function is given by:

$$
\frac{\partial C_{i}}{\partial d_{i}}=\frac{\partial f\left(w_{i}, \frac{d_{i}}{g_{i}}, p_{j}, u_{i}\right)}{\partial d_{i k}}
$$

The classical form of Cobb Douglas function used to be a popular choice of functional form for abatement cost functions. According to the data of Chinese industries and engineering literature suggestion of a joint cost function of pollution abatement for Chinese industry built up as (Wheeler, 1996):

$$
C(z)=c \cdot w^{\alpha} \prod_{i=1}^{n}\left[\frac{d_{i}}{g_{i}}\right]^{\beta_{i}}
$$

Abatement is measured by $d / g$, which reflects the percent reduction in the pollutant as it passes from pre-abatement influent concentration $g$ to post-abatement effluent concentration $d$.

\section{Model III. Modeling Sea Water Cleaning Project}

There is a sample project of Harbor Industrial Zone comprehensive utilization of seawater integration project in Tianjin City with the completion by 2010, which will provide 150 million tons industrial use water. Marine self-purification ability refers to the marine environment capacity to reduce the concentration of pollutants and even makes them disappear through its own physical, chemical and biological processes. Mainly includes three aspects: physical purification, chemical purification and biological purification. Self-purification can be expressed as: 


$$
S P C_{T}=S P C_{P}+S P C_{B}+S P C_{C}
$$

Where:

$S P C_{T}$ - total self-purification capacity

$S P C_{P}$ - physical self-purification capacity

$S P C_{B}$ - biological self-purification capacity

$S P C_{C}$ - chemical self-purification capacity

Time-specified pollutant stock change depends on pollutant supply, hydrodynamic transport of inner-outer seawater and total self-purification capacity.

$$
\dot{m}=F-T T F_{P-H D}-S P C_{T}
$$

Where:

$T T F_{P-H D}-$ Hydrodynamic transport of inner-outer seawater

The pollution stock can be expressed as:

$$
m_{t+1}=m_{0}+\int_{1}^{t}\left(F-T T F_{P-H D}-S P C_{T}\right) d t
$$

With industrial pollution abatement $z$, the function can be converted as:

$$
m_{t+1}=m_{0}+\int_{1}^{t}\left(F-z-T T F_{P-H D}-S P C_{T}\right) d t
$$

The function of unit time of pollutant transaction by hydrodynamic transport of inner-outer seawater (Wang, 2006) is as:

$$
-T T F_{P-H D}=\theta_{\text {oufflow }} \cdot Q_{\text {oufflow }} \cdot C_{\text {oufflow }}-\theta_{\text {in low }} \cdot Q_{\text {inf low }} \cdot C_{\text {inf low }}
$$

Where:

$\theta_{\text {inflow }}$ - water exchange rate of inflow

$\theta_{\text {outflow }}$ - water exchange rate of outflow

$C_{\text {inf low }}-$ pollution concentration of outer sea

$C_{\text {outflow }}$ - pollution concentration of the inner sea

$Q_{\text {inf low }}-$ natural flow form outer sea to inner sea

$Q_{\text {ouffow }}$ - natural flow from inner sea to outer sea

The stock function can be specified as:

$$
m_{t+1}=m_{0}+\int_{1}^{t}\left(F(y)-z-\left(\theta_{\text {oufflow }} \cdot Q_{\text {oufflow }} C_{\text {oufflow }}-\theta_{\text {inf low }} \cdot Q_{\text {inf low }} C_{\text {in low }}\right)\right) d t
$$

Suppose pollution concentration of inflow water from outer sea is zero according to background information, then $\theta_{\text {inf low }} \cdot Q_{\text {inflow }} \cdot C_{\text {inf low }}$ equal to zero. In this case we suppose $\theta_{\text {outflow }}=1$, thus inflow-outflow exchange rate equals to $100 \%$. The stock function is simplified as:

$$
m_{t+1}=m_{0}+\int_{1}^{t}\left(F(y)-z-Q_{\text {outflow }} \cdot C_{\text {outflow }}-S P C_{T}\right) d t
$$

Pollution growth under physical transfer and transform by sea water natural cycling: 


$$
\dot{m}=F(y)-z-q \cdot \frac{m}{\varepsilon \cdot v}-\varepsilon \cdot m
$$

Wheimedustrial pollution abatement

$q-$ natural outflow of sea water

$F(y)$ - industrial discharge

$\mathcal{E}-$ constant equals to $S P C_{T}$, total self-purification rate

The function of pollution stock

Where:

$$
m_{t+1}=m_{0}+\int_{1}^{t}\left(F(y)-z-q \cdot \frac{m}{\varepsilon \cdot v}-\varepsilon \cdot m\right) d t
$$

$q$ - natural outflow of sea water

Pollution stock under sea water cleaning project should be as following:

Subject to

$$
m_{t+1}=m_{0}+\int_{1}^{t}\left(F(y)-z-(s+q) \cdot \frac{m}{\varepsilon \cdot v}-\varepsilon \cdot m\right) d t
$$

$$
\begin{aligned}
& Q_{\text {outflow }}=s+q \\
& C_{\text {outflow }}=\frac{m}{\varepsilon \cdot v} .
\end{aligned}
$$

Change of pollution stock with sea water cleaning project

$$
\dot{m}=F(y)-z-(s+q) \cdot \frac{m}{\varepsilon \cdot v}-\varepsilon \cdot m
$$

5. Model IV. Dynamic Optimization of Pollution Abatement in the Bohai Sea Combining Industrial Abatement, Sea Water Cleaning Project and Fishery

The dynamic optimization problem combines two state equations in this optimal control problem, which correspond to two state variables fish stock $x$ and pollution stock $m$, respectively; four control variables industrial production $y$, volume of pollution abatement $z$, volume of sea water cleaning $S$ and catch of fish $h$, respectively. Cost of sea water abstraction is regarded as a part of cost fishery, since the original purpose of sea water cleaning project is to restore fish stock (Hart, 2003). To maximum benefit of fishery, we can follow and introduce the optimal solution of four control variables obtained from dynamic optimization. The objective function can be expressed as follows:

$$
\max _{y, z, h, s} \int_{0}^{\infty}[\Pi(h, x)+V(y)-C(z)-C(s)] \cdot e^{-r t} d t
$$

Subject to:

$$
\begin{gathered}
\Pi(h, x)=p(h) h-c(x) h^{2} \\
\dot{x}=G(x, m)-h \\
\dot{m}=F(y)-z-(s+q) \cdot \frac{m}{\varepsilon \cdot v}-\varepsilon \cdot m \\
x(0)=x_{0} \quad \lim _{t \rightarrow \infty} x(t)=x^{*}
\end{gathered}
$$




$$
m(0)=m_{0} \quad \lim _{t \rightarrow \infty} m(t)=m^{*}
$$

\section{Wheigitial fish stock}

$m_{0}-$ initial pollution stock

$x^{*}$ - optimal path of fish biomass

$m^{*}$ - optimal path of pollution loading

$p(h)$ - price of fish

$c(x)-$ cost of yield

$\Pi(h, x)$ - benefit of fishery

$G(x, m)$ - fish stock growth

$V(y)$ - industrial production benefit

$F(y)$ - production emission function

$C(z)-$ cost of industrial abatement

$C(s)$ - cost of sea water cleaning

The current Hamiltonian for this problem is:

$$
H=\Pi(h, x)+V(y)-C(z)-C(s)+\lambda(G(x, m)-h))+\mu\left(F(y)-z-(s+q) \cdot \frac{m}{\varepsilon \cdot v}-\varepsilon \cdot m\right)
$$

The necessary conditions of maximization are as follows:

$$
\begin{aligned}
& H_{h}=\pi_{h}-\lambda=0 \\
& H_{z}=-C^{\prime}(z)-\mu=0 \\
& H_{y}=V_{y}+\mu \cdot F_{y}=0 \\
& H_{s}=-C^{\prime}(s)-\mu \frac{m}{\varepsilon \cdot v}=0 \\
& \dot{\mu}-\delta \cdot \mu=-H_{m}=-\lambda \cdot G_{m}+\mu \cdot\left(\frac{s+q}{\varepsilon \cdot v}+\varepsilon\right) \\
& \dot{\lambda}-\delta \cdot \lambda=-H_{x}=-\left(\Pi_{x}-\lambda \cdot G_{x}\right)
\end{aligned}
$$

Where:

$\lambda-$ shadow value of fish stock

$\mu$-shadow value of pollution stock

According to the necessary conditions, the solution of the problem should be:

$$
\begin{aligned}
& \lambda=\Pi_{h} \\
& \Pi_{h h} \cdot \dot{h}-\delta \cdot \Pi_{h}=-\left(\Pi_{x}-\Pi_{h} \cdot G_{x}\right) \\
& \Pi_{h h} \cdot \dot{h}=-\left(\Pi_{x}-\Pi_{h} \cdot G_{x}\right)+\delta \cdot \Pi_{h} \\
& \dot{h}=\frac{\delta \cdot \Pi_{h}-\left(\Pi_{x}-\Pi_{h} \cdot G_{x}\right)}{\Pi_{h h}} \\
& \dot{h}=\frac{\Pi_{h}\left(\delta-G_{x}\right)-\Pi_{x}}{\Pi_{h h}}
\end{aligned}
$$




$$
\begin{aligned}
& \mu=-C^{\prime}(z) \\
& \dot{\mu}-\delta \cdot \mu=-H_{m}=-\lambda \cdot G_{m}+\mu \cdot\left(\frac{s+q}{\varepsilon \cdot v}+\varepsilon\right) \\
& -C^{\prime \prime}(z) \cdot \dot{z}+\delta \cdot C(z)=-\Pi_{h} \cdot G_{m}-C^{\prime}(z) \cdot\left(\frac{s+q}{\varepsilon \cdot v}+\varepsilon\right) \\
& C^{\prime \prime}(z) \cdot \dot{z}=\Pi_{h} \cdot G_{m}+C^{\prime}(z) \cdot\left(\frac{s+q}{\varepsilon \cdot V}+\varepsilon\right)+\delta \cdot C(z) \\
& \dot{z}=\frac{\Pi_{h} \cdot G_{m}+C^{\prime}(z) \cdot\left(\frac{s+q}{\mathcal{E} \cdot V}+\varepsilon\right)+\delta \cdot C(z)}{C^{\prime \prime}(z)} \\
& H_{y}=V_{y}+\mu \cdot F_{y}=0 \\
& V_{y}=-\mu \cdot F_{y} \\
& V_{y}=C^{\prime}(z) \cdot F_{y} \\
& V_{y y} \cdot \dot{y}=C^{\prime}(z) \cdot F_{y} \\
& \dot{y}=\frac{C^{\prime}(z) \cdot F_{y}}{\dot{y}} \\
& H_{s}=-C^{\prime}(s)-\mu \frac{m}{\mathcal{E} \cdot v}=0 \\
& -C^{\prime \prime}(s) \cdot \dot{s}+C^{\prime}(z) \cdot \frac{m}{\varepsilon \cdot v}=0 \\
& \dot{s}=\frac{-C^{\prime}(z) \cdot \frac{m}{\mathcal{E} \cdot v}}{C^{\prime \prime}(z)}=-\frac{m \cdot C^{\prime}(z)}{\varepsilon \cdot v \cdot C^{\prime \prime}(z)}
\end{aligned}
$$

Summary of the results as following:

$$
\begin{gathered}
\dot{z}=\frac{\Pi_{h} G_{m}+\left(\frac{s+q}{\varepsilon \cdot v}+\varepsilon+\delta\right) C^{\prime}(z)}{C^{\prime \prime}(z)} \\
\dot{h}=\frac{\left(\delta-G_{x}\right) \Pi_{h}-\Pi_{x}}{\Pi_{h h}} \\
\dot{y}=\frac{C^{\prime}(z) F_{y}}{V_{y y}} \\
\dot{s}=\frac{m \cdot V(y)}{\varepsilon \cdot v \cdot F(y) C^{\prime \prime}(s)}=\frac{m \cdot C^{\prime}(z)}{\varepsilon \cdot v \cdot C^{\prime \prime}(s)}
\end{gathered}
$$

\section{Conclusion}

The paper sets up a frame work which modeling the optimal path of industrial abatement under tradable permit and seawater cleaning project. Three sub-models are set up which reveal pollution-fish stock interaction, industrial pollution abatement under tradable permit, seawater cleaning project, respectively. Then fourth sub-model is dynamic optimization problem which combines industrial pollution abatement, sea water cleaning volume and fishery, to maximum total benefits of industry and fishery. To maximum benefit of fishery, we follow and introduce the optimal solution of four control variables obtained from dynamic optimization.

\section{References}

China's Statistic Yearbook. (2008). Retrieved from http://www.stats.gov.cn/tijsj/ndsj/

Collins, A., Stapleton, M., \& Whitmarsh, D. (1998). Fishery-pollution interactions: a modelling approach to explore the nature and incidence of economic damages. Marine Pollution Bulletin, 36(3), 211-221.

Dasgupta, S., Huq, M., Wheeler, D., \& Zhang, C. (2001). Water pollution abatement by Chinese industry: cost estimates and policy implications. Applied Economics, 33(4), 547-557. 
Dasgupta, S., NI. H., \& Wheeler, D. (1997). Bending the Rules: Discretionary Pollution Control in China. World Bank Policy Research Department Working

Hart, R. (2003). Dynamic pollution control - time lags and optimal restoration of marine ecosystems. Ecological Economics, 47(1), 79-93.

Li, S. D., Hu, W., \& Gu, M. D. (2008). On control strategy and process of pollution abatement investment in the condition of emission trading. Systems Engineering-Theory \& Practice, 2, 022.

Liu, Y. X., \& Luo, B. (2006). Multi-sectoral Co-operation in Bohai Sea Pollution Control Makes More Pollution. Economic Information Daily. Retrieved from http://www.eastmoney.com

Marine Environment Quality of the Bohai Sea. (2009). Retrieved from http://www.doc88.com/ p-8018027608059.html

National Marine Environment Quality Bulletins. (2004-2009). Retrieved from http://www.soa.gov.cn/zwgk/ hygb/gjhyjgb/201609/t20160908_53180.html

National Science Committee. (1990). Retrieved from http://www.most.gov.cn/

Richard, A., Vollenweider, J., Talling, F., \& Westlake, D. F. (1974). Primary Production in Aquatic Environments. Blackwell, Oxford.

State Council. (2008). Industrial Pollution Emission Coefficient Manual from The First National Census on Pollution Sources.

Wang, X. L., \& Li, K. Q. (2006). The Standard Self- Purification Capacity - Marine Environmental Capacity of Major chemical contaminants in the Bohai Sea (pp. 155-157). Science Pubilishing House, Beijing.

Welch, E. B. (1992). Ecological Effects of Wastewater: Applied Limnology and Pollutant Effects (2nd ed.). Chapman and Hall, London.

Zheng, Y. (2007). China Destruction- Ecological Collapse Report in the emergency. Retrieved from http://www.aboluowang.com/life/data/2007/0122/article_7070.html

\section{Copyrights}

Copyright for this article is retained by the author(s), with first publication rights granted to the journal.

This is an open-access article distributed under the terms and conditions of the Creative Commons Attribution license (http://creativecommons.org/licenses/by/4.0/). 